\title{
Intra-individual Variation of the Cuff-Leak Test as a Predictor of Post-Extubation Stridor
}

\author{
Antoine Gros MD, Laurent Holzapfel MD, Sophie Marqué MD, Laurent Perard MD, \\ Guy Demingeon MD, Bonavie Piralla MD, Sandrine Gaillard MD, and Xavier Tchenio MD
}

\begin{abstract}
BACKGROUND: This was an evaluation of intra-individual variation of the cuff-leak test ( $\triangle$ CLT) immediately post-intubation and pre-extubation, as a predictor of post-extubation stridor. METHODS: Prospective, clinical investigation in the ICU of a non-university hospital. CLTs were performed immediately after intubation (T0) and before extubation (T1) to evaluate the differences in cuff leak $\left(\Delta C L T=C_{T 1}-C L_{T 0}\right)$. RESULTS: We included 104 mechanically ventilated subjects in the study over a 12-month period. The incidence of post-extubation stridor was $6.7 \%$. Stridor was more common in females of short stature. $\triangle$ CLT was considered as significant when $C_{\mathrm{T} 1}-\mathbf{C L}_{\mathrm{T} 0}$ was negative. The sensitivity and the specificity of the test were $86 \%$ and $48 \%$, respectively. When we tested the pre-extubation CLT alone with a threshold of $130 \mathrm{~mL}$ as a predictor of post-extubation stridor, the sensitivity and the specificity of the test were $86 \%$ and $76 \%$, respectively. CONCLUSIONS: The intra-individual variation of CLT immediately post-intubation and preextubation does not improve the accuracy of a standard pre-extubation CLT to predict postextubation stridor. Moreover, the standard pre-extubation CLT did not appear in our study to be an ideal test to detect post-extubation stridor. Larger studies should be performed before generalizing these preliminary results. Key words: cuff-leak test; mechanical ventilation; weaning; postextubation stridor; upper-airway obstruction; critically ill patient. [Respir Care 2012;57(12):2026-2031. (C) 2012 Daedalus Enterprises]
\end{abstract}

\section{Introduction}

Stridor following extubation in the ICU occurs in 2-25\% of all patients, leading to reintubation in approximately $1 \%$

Drs Gros and Marqué are affiliated with the Intensive Care Unit, René Dubos Hospital, Pontoise, France. Drs Gros, Holzapfel, Demingeon, Piralla, Gaillard, and Tchenio are affiliated with the Intensive Care Unit, Fleyriat Hospital, Bourg-en-Bresse, France. Dr Perard is affiliated with the Department of Internal Medicine, Edouard Herriot University Hospital, Lyon, France.

The authors have disclosed no conflicts of interest.

Dr Gros presented a version of this paper at the annual congress of the Société de Réanimation de Langue Française, held October 13, 2005, in Paris, France.

Correspondence: Antoine Gros MD, Intensive Care Unit, René Dubos Hospital, 6 Avenue de l'Ile de France, BP 79, 95303 Cergy-Pontoise Cedex. E-mail: antoinegros6@gmail.com.

DOI: $10.4187 /$ respcare. 01527 of the cases. ${ }^{1-6}$ In a recent study, corticosteroids were proposed as a preventive treatment of laryngeal edema before planned extubation, when administered to subjects mechanically ventilated for $>36$ hours. ${ }^{6}$ Despite the identification of additional risk factors (female, short stature), post-extubation laryngeal edema remains a poorly predictable complication.

See the Related Editorial on Page 2136

In order to select patients who might best benefit from preventive treatment, the cuff-leak test (CLT) has been proposed as a simple and noninvasive procedure to identify high-risk patients. ${ }^{7}$ Despite improvements made to the original qualitative test, by quantification of the leak volume (inspired minus exhaled tidal volume during mechanical ventilation) or the fraction of the leak volume,${ }^{8}$ the positive predictive value of a failed CLT remains fairly low in adults. Indeed a recent meta-analysis looked at 11 prospective studies on CLT, including 
more than 50 patients. It concluded that there was a possible but limited use for this test for predicting postextubation airway obstruction, with a sensitivity of 0.56 $(95 \%$ CI $0.48-0.63)$ and a specificity of $0.92(95 \%$ CI $0.90-0.93){ }^{9}$

The ratio of the diameter of the endotracheal tube to that of the larynx on leak volumes has never been studied, but might influence CLT accuracy. A negative preextubation CLT might be explained either by a large endotracheal tube in a small larynx or by laryngeal edema. To examine these potential confounding factors, we tested the hypothesis that the intra-individual variation of the CLT between immediate post-intubation and pre-extubation periods ( $\triangle$ CLT) might be a better predictive factor of post-extubation stridor than simply the pre-extubation CLT. A secondary objective was to compare the accuracy of the $\triangle$ CLT to the accuracy of a standard pre-extubation CLT in predicting post-extubation stridor.

\section{Methods}

\section{Study Design}

This prospective study was conducted over a 12-month period in a 10-bed medical and surgical ICU at Fleyriat Hospital, a general hospital in Bourg-en-Bresse, France. The ICU staff includes 6 intensivist-trained physicians. There is always at least one of them present in the ICU. This study protocol was approved by the ethical committee of the Société de Réanimation de Langue Française, which waived the requirement for informed consent.

\section{Study Subjects}

The eligibility criteria for the study were: age $>18$ years, necessity for intubation after ICU admission, and planned extubation during ICU stay. Patients were excluded if they died before the weaning process was achieved, if they needed a tracheostomy, if the duration of mechanical ventilation was shorter than 48 hours, or if there was unplanned extubation.

\section{Procedures}

All subjects were intubated and ventilated in accordance with standard-of-care practices, or at the discretion of the attending physician. Endotracheal tubes were all of 7-8 $\mathrm{mm}$ internal diameter, and cuff pressure was maintained below $30 \mathrm{~cm} \mathrm{H}_{2} \mathrm{O}$. For each subject the following characteristics were recorded: age, sex, height, weight, reason for admission, severity of illness, organ failure score (Simplified

\section{QUICK LOOK}

\section{Current knowledge}

Stridor following extubation in the ICU occurs in 2-25\% of all patients, leading to reintubation in approximately $1 \%$ of the cases The cuff-leak test has been proposed as a simple and noninvasive procedure to identify patients at high risk for post-extubation stridor.

\section{What this paper contributes to our knowledge}

The intra-individual variation of cuff-leak testing immediately post intubation and pre extubation does not improve the accuracy of a standard pre-extubation cuffleak test to predict post-extubation stridor. The standard pre-extubation cuff-leak test does not reliably detect post-extubation stridor.

Acute Physiology Score II), duration of intubation, internal diameter of the cuffed tube, and results of both CLTs (following intubation and preceding extubation). Evaluation for extubation readiness was made according to national guidelines, independent of CLT results. ${ }^{10}$ The occurrence of post-extubation stridor within 48 hours of extubation was recorded. Post-extubation stridor was clinically defined as the development of laryngeal dyspnea after extubation, associated with respiratory distress. Subjects developing post-extubation stridor were first treated with epinephrine and corticosteroids nebulization before reintubation was considered by the physicians in charge. Incidence of reintubation due to post-extubation stridor was also recorded.

CLT was performed on 2 occasions for each subject included in the study: the first CLT was acquired within the hour following intubation (T0) and the second within the hour preceding extubation (T1). CLT was performed by all physicians of the unit, as initially described by Miller and Cole. ${ }^{7}$ The subject was placed in the semi-Fowler position, oral and tracheal suction were performed, and the subject was placed on assist-control ventilation mode with the following parameters: respiratory rate 15 breaths $/ \mathrm{min}$, $\mathrm{F}_{\mathrm{IO}_{2}}$ 1.0, PEEP $0 \mathrm{~cm} \mathrm{H} \mathrm{H}_{2} \mathrm{O}$, and tidal volume $10 \mathrm{~mL} / \mathrm{kg}$ ideal weight. ${ }^{11} \mathrm{~A}$ few respiratory cycles were needed to equalize inspired and exhaled volumes with an acceptable error margin of $20 \mathrm{~mL}$. The endotracheal tube cuff was then deflated, and the operator waited for a few respiratory cycles (to allow the subject to cough) before performing the measurements. The exhaled tidal volume was recorded over 6 respiratory cycles. The cuff leak (CL) was calculated as the difference between the mechanical inspired volume and the average of the 3 lowest exhaled volumes. 


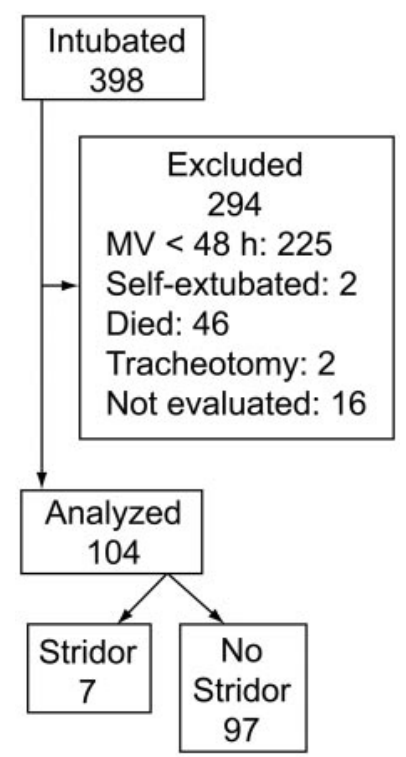

Fig. 1. Distribution of intubated subjects during the study period.

The variation of CLT for each subject, between T0 and T1 was defined as $\Delta \mathrm{CLT}=\mathrm{CL}_{\mathrm{T} 1}-\mathrm{CL}_{\mathrm{T} 0}$.

\section{Statistical Analysis}

Discrete variables were expressed as percentage, and continuous variables as mean $\pm \mathrm{SD}$ for variables normally distributed, and as medians with interquartiles for nonnormally distributed variables. Differences between subjects with and without post-extubation stridor leading to reintubation were compared using the Student $t$ test for continuous and normally distributed variables. The MannWhitney U test was used to compare continuous and nonnormally distributed variables, and the Fisher exact test was used for categorical data. Subjects presenting with missing CLT were considered as censored data and were not included in the statistical analysis. Significance was reported at a $P$ value of .05 or less.

The variation of CLT was defined as a negative test when $\triangle$ CLT was positive (ie, when CL was higher at the time of post-intubation than at the time of pre-extubation, and positive test when $\Delta$ CLT was $<0$ ). Receiver-operating characteristic (ROC) curves were created for $\triangle \mathrm{CLT}$ and single pre-extubation CLT, and permitted calculation of sensitivity, specificity, positive predictive value, and negative predictive value and their $95 \%$ confidence intervals. Sensitivity, specificity, positive predictive value, and negative predictive value for $\Delta$ CLT were calculated with this threshold of $0 \mathrm{~mL}$. The single pre-extubation CLT threshold value for optimum test discrimination was determined by ROC curves. ${ }^{12}$ Sensitivity, specificity, positive predictive value, and negative predictive value of the single pre-extubation
Table 1. Characteristics of Subjects

\begin{tabular}{|c|c|c|c|}
\hline & $\begin{array}{l}\text { No Stridor } \\
(n=97)\end{array}$ & $\begin{array}{l}\text { Stridor } \\
(n=7)\end{array}$ & $P$ \\
\hline Age, median (IQR) y & $71(56-77)$ & $82(66-84)$ & .18 \\
\hline Male/female, no. & $71 / 26$ & $1 / 6$ & $<.01$ \\
\hline Weight, mean \pm SD kg & $74 \pm 18$ & $69 \pm 12$ & .34 \\
\hline SAPS II, mean \pm SD & $51 \pm 13$ & $54 \pm 17$ & .15 \\
\hline \multicolumn{4}{|l|}{$\begin{array}{l}\text { Reason for ICU Admission, } \\
\text { no. }(\%)\end{array}$} \\
\hline Surgical & $18(16)$ & $1(14)$ & .20 \\
\hline Medical & $79(84)$ & $6(86)$ & .18 \\
\hline Septic shock & $9(9)$ & $0(0)$ & \\
\hline COPD & $12(12)$ & $0(0)$ & \\
\hline Coma & $23(24)$ & $3(43)$ & \\
\hline Pneumonia & $21(22)$ & $1(14)$ & \\
\hline Other & $14(14)$ & $2(28)$ & \\
\hline ETT diameter, mean \pm SD $\mathrm{mm}$ & $7.5 \pm 0.2$ & $7.3 \pm 0.4$ & .36 \\
\hline Days of MV, median (IQR) d & $5(3-9)$ & $4(3-5)$ & .17 \\
\hline ICU stay, median (IQR) d & $10(6-16)$ & $10(9-12)$ & .30 \\
\hline
\end{tabular}

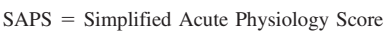

CLT were calculated with this threshold. Data were analyzed with commercially available software (MedCalc 10.4, MedCalc Software, Mariakerke, Belgium).

\section{Results}

Figure 1 shows the trial profile. During the study period, 398 subjects were intubated and mechanically ventilated in the ICU. Reasons for exclusion from the study included: duration of mechanical ventilation $<48$ hours $(n=225)$, death before achievement of weaning process $(n=46)$, unplanned extubation $(n=5)$, tracheostomy $(n=2)$, and missing data $(n=16)$. Data on the remaining 104 subjects were included in the analysis. Table 1 shows the baseline characteristics of the study population. The main reasons for admission to ICU were medical $(n=85)$. Post-extubation stridor occurred in 7 cases $(6.7 \%)$, all within the 12 hours following extubation. Six subjects required tracheal reintubation within the 48 hours following extubation in the stridor group $(n=7)$, and 23 subjects in the nostridor group $(n=97)$. Table 1 shows the results of univariate analysis undertaken to identify risk factors for post-extubation stridor. Subjects who developed this complication were mainly women. Duration of mechanical ventilation was similar in both groups, with a median of 5 days (IQR 3-9 d) in the overall population.

Table 2 shows the main characteristics of the post-extubation stridor group and their individual pre-extubation CLT and $\triangle$ CLT values. ROC curves for $\triangle$ CLT and single pre-extubation CLT are represented in Figure 2. The diagnostic abilities of the $\Delta$ CLT and single pre-extubation 


\section{Cuff-Leak Test as a Predictor of Post-Extubation Stridor}

Table 2. Main Characteristics, Values of Pre-extubation Cuff-Leak Test, and Individual Cuff-Leak Test Volume Variations for the 7 Cases of Stridor

\begin{tabular}{|c|c|c|c|c|c|c|}
\hline $\begin{array}{l}\text { Subject } \\
\text { No. }\end{array}$ & Age, $y$ & Sex & SAPS II & $\begin{array}{l}\text { Days } \\
\text { of MV }\end{array}$ & $\begin{array}{c}\text { Cuff-Leak Test } \\
\text { Volume, mL }\end{array}$ & $\begin{array}{l}\Delta \text { Cuff-Leak Test } \\
\text { Volume, mL }\end{array}$ \\
\hline 1 & 91 & F & 82 & 2 & -68 & -431 \\
\hline 2 & 85 & F & 66 & 5 & 100 & -260 \\
\hline 3 & 65 & F & 44 & 5 & 30 & -90 \\
\hline 4 & 82 & F & 57 & 4 & 40 & -80 \\
\hline 5 & 82 & F & 44 & 2 & 0 & -10 \\
\hline 6 & 68 & $\mathrm{~F}$ & 29 & 10 & 205 & -5 \\
\hline 7 & 61 & M & 53 & 4 & 130 & 130 \\
\hline
\end{tabular}

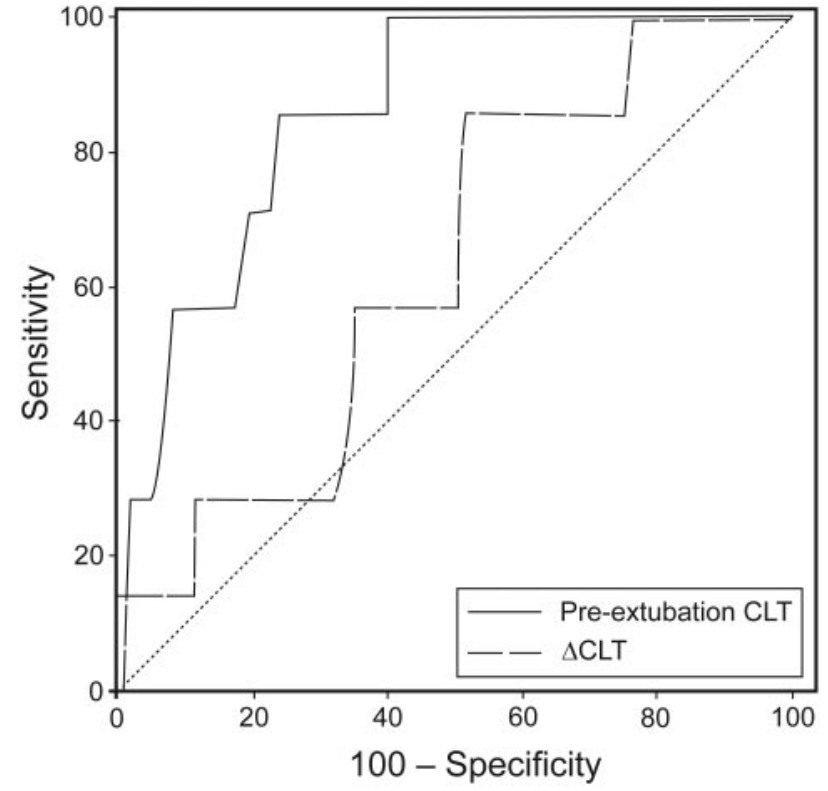

Fig. 2. Receiver operating characteristic (ROC) curves for variation in cuff-leak test $(\triangle C L T)$ and single pre-extubation CLT. True positive and true negative fractions are plotted on the $Y$ axis and $\mathrm{X}$ axis, respectively.

CLT in predicting post-extubation stridor were not similar, with an area under the ROC curve of 0.63 (95\% CI 0.53 0.72 ) for the $\Delta$ CLT and 0.86 (95\% CI 0.78-0.92) for the single pre-extubation stridor $(P=.01)$. Sensitivity, specificity, positive likelihood ratio, and negative likelihood ratio of $\triangle$ CLT were calculated with the threshold of $0 \mathrm{~mL}$ and were of $86 \%$ (95\% CI $42-100 \%), 48 \%$ (95\% CI $38-$ 59\%), 1.7 (95\% CI 1.2-2.4), and 0.3 (95\% CI $0.1-1.8$ ), respectively. Positive predictive value and negative predictive value raised to $11 \%(95 \% \mathrm{CI} 4-22 \%)$ and $98 \%$ (95\% CI 89-100\%), respectively.
As far as single pre-extubation CLT values were concerned, an absolute volume $<130 \mathrm{~mL}$ was found to predict post-extubation stridor and was considered as a positive CLT, with a sensitivity of $86 \%$ (95\% CI $42-100 \%$ ), a specificity of $76 \%$ (95\% CI $67-84 \%$ ), a positive likelihood ratio of 3.6 (95\% CI 2.6-5.0), and a negative likelihood ratio of 0.2 (95\% CI $0.03-1.2$ ). In our study, with an incidence of post-extubation stridor of $6.7 \%$, the positive and negative predictive values of a single pre-extubation CLT were $21 \%(95 \%$ CI $8-40 \%)$ and $99 \%(95 \%$ CI 93-100\%), respectively.

\section{Discussion}

In this study we evaluated the individual variation of CLT between post-intubation and pre-extubation as a predictor of post-extubation stridor. This composite test proved to be of limited value, with a poor positive predictive value and a good negative predictive value. A single pre-extubation CLT predicted better which subjects would require an escalation of care, possibly culminating in reintubation, which was comparable to previous reports. $4,5,7,8,13$ The incidence of post-extubation stridor in our population was $6.7 \%$ (7 subjects out of 104), which was low, although in agreement with most clinical studies. ${ }^{1-6}$ Although CLT sensitivity was high, its poor specificity and the low incidence of post-extubation stridor explained why the CLT had a poor positive predictive value. If used at all, the CLT should therefore be used in a high-risk population to select patients that may benefit from a preventive treatment. Because of the limited number of subjects, we could not make any post-hoc analysis of groups presenting one or more of the following risk factors: female sex, high organ failure and severity, prolonged over-inflated cuff, high duration of mechanical ventilation, and history of laryngeal trauma. $^{4}$ 


\section{Cuff-Leak Test as a Predictor of Post-Extubation Stridor}

We made the hypothesis that measuring CLT immediately after intubation would demonstrate the possible influence of the ratio of endotracheal tube diameter to laryngeal size on leak volumes. One reason to explain the lack of superiority of $\triangle \mathrm{CLT}$ over a single pre-extubation CLT could be the difficulty in achieving a standardized CLT at 2 different times during the subject's ICU stay: use of sedatives and neuromuscular blockade for induction, as opposed to awareness and active participation of the subject at the time of the second CLT, could lead to an uninterpretable $\Delta$ CLT value. Another reason could be changes in pulmonary compliance between intubation and extubation. Indeed, Prinianikis et al suggested in 2005 that cuff leak could be influenced by compliance of the respiratory system and inspiratory flow. ${ }^{14}$ As these results were not released when our study was designed, data regarding compliance were not collected.

Moreover, in our study, the diagnosis of post-extubation stridor remained clinical and therefore subjective. Laryngeal edema documented at laryngoscopy during reintubation is a more objective end point, with a reported incidence of between $37 \%$ and $60 \% .15,16$ Non-relevant laryngeal lesions could possibly be clinically undetectable but still demonstrated by CLT, leading to a false interpretation of the test.

In addition, 6 subjects were reintubated within 48 hours after extubation in the stridor group, while one subject remained free from reintubation in this group. These results are comparable to those of previous studies. ${ }^{17,18} \mathrm{In}$ the no-stridor group, 23 of the 97 subjects required reintubation within the 48 hours following extubation. The cause of reintubation was not laryngeal edema, as attested by laryngoscopy. Lastly, CLT reproducibility has often been questioned, and may be a limiting factor in our study. Pettignano et al found that a standardized procedure, performed after sedation and curarization of the patient, guaranteed a reliable cuff-leak measure. ${ }^{19}$ However, these ideal conditions for measurement can never be obtained in the hour preceding planned extubation. In an attempt to exclude erroneous values, leak volumes were observed and averaged over several respiratory cycles, but in clinical practice pre-extubation CLT may be inaccurate due to agitation and coughing after cuff deflation.

In our population, female sex and short stature were associated with a higher occurrence of stridor after extubation, as reported in other studies. ${ }^{1,7}$ Yet our results did not confirm the relationship between post-extubation stridor and other reported risk factors such as medical admission, traumatic intubation, Simplified Acute Physiology Score II, and duration of intubation. ${ }^{1,4,8}$ This can be explained by the fact that, in our study, all of the subjects were intubated according to the same protocol, and were all mechanically ventilated for longer than 48 hours.

\section{Conclusions}

The intra-individual variation of the CLT between immediate post-intubation and pre-extubation is an unreliable predictor of post-extubation stridor and does not improve the accuracy of the standard pre-extubation CLT to predict post-extubation stridor. Due to the small number of stridor cases the standard pre-extubation CLT does not appear in our study to be an ideal test. Larger investigations are needed before these results can be generalized.

\section{REFERENCES}

1. Darmon JY, Rauss A, Dreyfuss D, Bleichner G, Elkharrat D, Schlemmer B, et al. Evaluation of risk factors for laryngeal edema after tracheal extubation in adults and its prevention by dexamethasone. A placebo-controlled, double-blind, multicenter study. Anesthesiology 1992;77(2):245-251.

2. Ho LI, Harn HJ, Lien TC, Hu PY, Wang JH. Postextubation laryngeal edema in adults. Risk factor evaluation and prevention by hydrocortisone. Intensive Care Med 1996;22(9):933-936.

3. Anene O, Meert KL, Uy H, Simpson P, Sarnaik AP. Dexamethasone for the prevention of postextubation airway obstruction: a prospective, randomized, double-blind, placebo-controlled trial. Crit Care Med 1996;24(10):1666-1669.

4. Jaber S, Chanques G, Matecki S, Ramonatxo M, Vergne C, Souche $\mathrm{B}$, et al. Post-extubation stridor in intensive care unit patients. Risk factors evaluation and importance of the cuff-leak test. Intensive Care Med 2003;29(1):69-74.

5. Kriner EJ, Shafazand S, Colice GL. The endotracheal tube cuff-leak test as a predictor for postextubation stridor. Respir Care 2005;50(12): 1632-1638.

6. Francois B, Bellissant E, Gissot V, Desachy A, Normand S, Boulain $\mathrm{T}$, et al. 12-h pretreatment with methylprednisolone versus placebo for prevention of postextubation laryngeal oedema: a randomised double-blind trial. Lancet 2007;369(9567):1083-1089.

7. Miller RL, Cole RP. Association between reduced cuff leak volume and postextubation stridor. Chest 1996;110(4):1035-1040.

8. Sandhu RS, Pasquale MD, Miller K, Wasser TE. Measurement of endotracheal tube cuff leak to predict postextubation stridor and need for reintubation. J Am Coll Surg 2000;190(6):682-687.

9. Ochoa ME, Marin Mdel C, Frutos-Vivar F, Gordo F, Latour-Perez J, Calvo E, et al. Cuff-leak test for the diagnosis of upper airway obstruction in adults: a systematic review and meta-analysis. Intensive Care Med 2009;35(7):1171-1179.

10. Richard CB, Cantagrel S, Cuvelier A, Fauroux B, Garo BH, Lesieur $\mathrm{O}$, et al. Sevrage de la ventilation mécanique (à l'exclusion du nouveau-né et du réveil d'anesthésie). Réanimation 2001;10:699-705. Article in French.

11. The Acute Respiratory Distress Syndrome Network. Ventilation with lower tidal volumes as compared with traditional tidal volumes for acute lung injury and the acute respiratory distress syndrome. N Engl J Med 2000;342(18):1301-1308.

12. Zweig MH, Campbell G. Receiver-operating characteristic (ROC) plots: a fundamental evaluation tool in clinical medicine. Clin Chem 1993;39(4):561-577

13. De Bast Y, De Backer D, Moraine JJ, Lemaire M, Vandenborght C, Vincent JL. The cuff leak test to predict failure of tracheal extubation for laryngeal edema. Intensive Care Med 2002;28(9): 1267-1272. 


\section{Cuff-Leak Test as a Predictor of Post-Extubation Stridor}

14. Prinianakis G, Alexopoulou C, Mamidakis E, Kondili E, Georgopoulos D. Determinants of the cuff-leak test: a physiological study. Crit Care 2005;9(1):R24-R31.

15. Kastanos N, Estopa Miro R, Marin Perez A, Xaubet Mir A, AgustiVidal A. Laryngotracheal injury due to endotracheal intubation: incidence, evolution, and predisposing factors. A prospective longterm study. Crit Care Med 1983;11(5):362-367.

16. Chung YH, Chao TY, Chiu CT, Lin MC. The cuff-leak test is a simple tool to verify severe laryngeal edema in patients undergoing long-term mechanical ventilation. Crit Care Med 2006;34(2):409414.

17. Sukhupanyarak S. Risk factors evaluation and the cuff leak test as predictors for postextubation stridor. J Med Assoc Thai 2008;91(5): 648-653.

18. Efferen LS, Elsakr A. Post-extubation stridor: risk factors and outcome. J Assoc Acad Minor Phys 1998;9(4):65-68.

19. Pettignano R, Holloway SE, Hyman D, LaBuz M. Is the leak test reproducible? South Med J 2000;93(7):683-685.

This article is approved for Continuing Respiratory Care Education credit. For information and to obtain your CRCE

(free to AARC members) visit www.rcjournal.com 